\title{
Namibia has a strong foundation for implementing the treat all guidelines and reaching the UNAIDS 90-90-90 targets
}

Project SOAR

Follow this and additional works at: https://knowledgecommons.popcouncil.org/departments_sbsr-hiv

Part of the Demography, Population, and Ecology Commons, Family, Life Course, and Society Commons, Health Policy Commons, and the International Public Health Commons How does access to this work benefit you? Let us know!

\section{Recommended Citation}

Project SOAR. 2018. "Namibia has a strong foundation for implementing the treat all guidelines and reaching the UNAIDS 90-90-90 targets," Project SOAR Results Brief. Washington, DC: Population Council. 


\section{Namibia Has a Strong Foundation for Implementing the Treat All Guidelines and Reaching the UNAIDS 90-90-90 Targets}

In late 2015, the World Health Organization (WHO) announced new "treat all" guidelines, recommending that anyone who has tested positive for HIV should begin antiretroviral treatment (ART) as soon as possible. ${ }^{1}$ The Government of Namibia adopted these guidelines and included treat all in their 2016 National Guidelines for ART; ${ }^{2}$ nationwide implementation began in April 2017. There is a need to understand how the implementation of these new guidelines affects critical aspects of ART service quality as reflected by patient-level outcomes including 12-month retention, appointment attendance, and viral suppression, and health system outcomes (i.e., human and financial resources for health).

Besides the implementation of the treat all guidelines, the Namibian government began piloting ART task shifting and service decentralization since 2011 and officially adopted task-shifting guidelines in 2015. This process involves transferring stable ART clients from district-level hospitals to smaller community health centers and devolving specific point-ofcare responsibilities from physicians to nurses. Task shifting intends to help the country's health system cope with the severe shortage of medical staff while service decentralization aims to expand access to ART in rural areas-each simultaneously reducing patient loads in often heavily burdened central health centers.

This brief highlights baseline data collected as part of a larger study assessing the impact of implementing the treat-all guidelines on key treatment and health system outcomes. The second round of data collection will be completed in June-July 2018. The baseline data provide

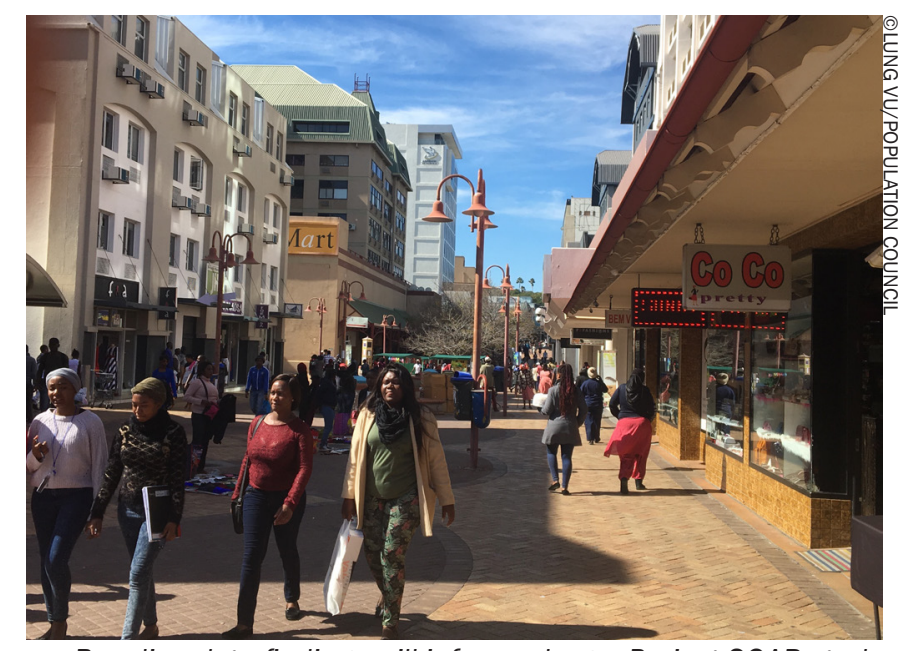

Baseline data findings will inform a larger Project SOAR study assessing the impact of implementing the treat-all guidelines on key treatment and health system outcomes in Namibia.

\section{KEY MESSAGES}

- Overall, data from 10 selected ART sites show that the Namibian government is progressing toward achieving the UNAIDS 90-90-90 targets.

- Providing services through decentralized, community-based health facilities can expand access to HIV care and treatment in rural areas without compromising key patient outcomes. This effort should be continued.

- Additional research is needed to better understand why only 60 percent of ART patients had records of viral load data and to identify solutions to close this gap. 
a snapshot of ART services delivered by health facilities in northern Namibia during the year prior to the rollout of the treat all guidelines. We also examine ART service outcomes, including 12-month ART patient retention, viral load (VL) testing, and viral suppression, to determine the effects of service decentralization during the year preceding the national roll-out of Namibia's treat all recommendations.

\section{METHODS}

We selected six central district hospitals (defined as centralized sites) and four community-based health centers (defined as decentralized sites) from six districts in northern Namibia (Andara, Nyangana, Oshikuku, Onandjokwe, Tsumeb, and Omuthiya). These 10 selected facilities have received technical assistance for HIV clinical services from IntraHealth International (UTAP Project) since 2015.

We abstracted information on clinical visits, scheduled appointments, drug dispensing, and VL tests from the records of 949 patients for the period 1 April 2016 to 31 March 2017.

\section{DEFINITIONS}

Viral suppression: having a VL test
result of $<1,000$ copies/ml

Because the length of time on ART may affect treatment outcomes, we stratified ART patients as follows:

- New ART patients: those who initiated ART between 1 January and 31 March 2016.

- Existing ART patients: those who initiated treatment prior to 1 January 2016.

\section{PROFILE OF PEOPLE RECEIVING ART SERVICES}

\begin{tabular}{|c|c|c|c|}
\hline & & $\begin{array}{c}\text { Hospital } \\
\text { (Central) }\end{array}$ & $\begin{array}{c}\text { Clinic } \\
\text { (Decentral) }\end{array}$ \\
\hline Sex & & $\begin{array}{c}66 \% \\
\text { female }\end{array}$ & $\begin{array}{c}72 \% \\
\text { female }\end{array}$ \\
\hline & Mean* & $\begin{array}{c}41 \text { years } \\
\text { old }\end{array}$ & $\begin{array}{c}44 \text { years } \\
\text { old }\end{array}$ \\
\hline $\begin{array}{l}\text { Marital } \\
\text { status }\end{array}$ & $\begin{array}{l}\text { Single/unmarried } \\
\text { (incl. divorced, } \\
\text { widowed, } \\
\text { separated)** } \\
\text { Married/in union }\end{array}$ & $\begin{array}{l}68 \% \\
27 \%\end{array}$ & $\begin{array}{l}56 \% \\
38 \%\end{array}$ \\
\hline & New ART & $29 \%$ & $13 \%$ \\
\hline $\begin{array}{c}\text { Patient } \\
\text { type }\end{array}$ & Existing ART & $71 \%$ & $87 \%$ \\
\hline
\end{tabular}

Overall, women comprised over two-thirds of the sample, but gender differences between the two facility types was not significant. On average, patients at central facilities were 2.5 years younger, more likely to be single/unmarried, and new ART patients compared to their decentralized counterparts. Patients' median time on ART across both facilities was 5.5-5.7 years.

\section{RESULTS}

\section{Health facilities achieved $>90$ percent patient retention over 12 months, but more than a third of patients missed at least one scheduled ART refill visit (Figure 1).}


Figure 1 Client-level care outcomes during the past 12 months

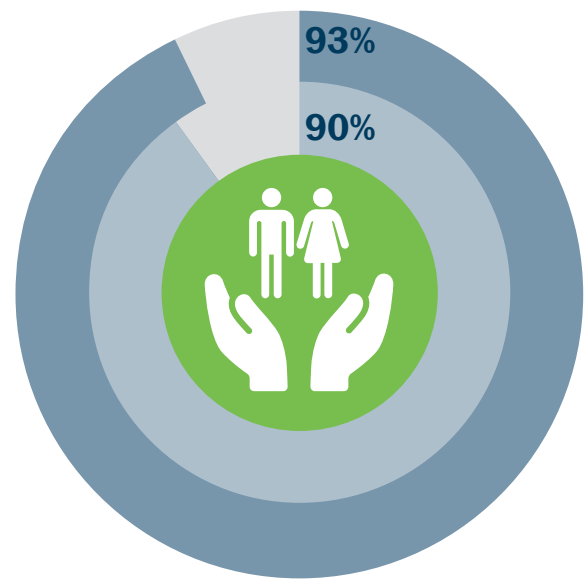

Retained in care

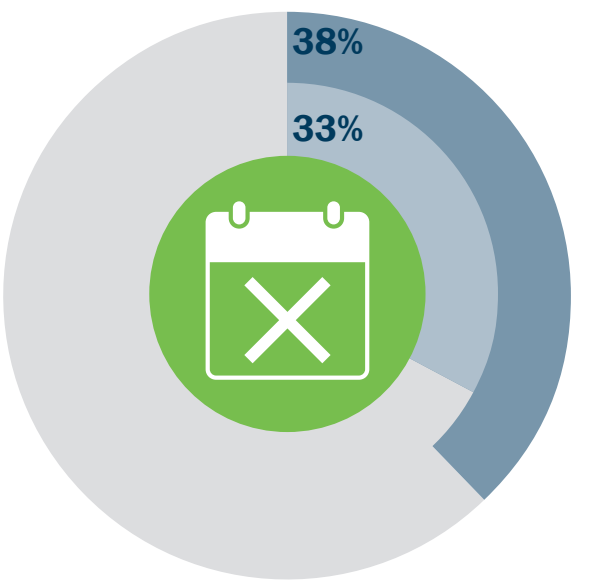

Missed $\geq 1$ scheduled visits
Patients at central facilities were more likely to have received a VL test than patients at decentralized sites.

Overall, the records of less than two-thirds of patients (60 percent) at either facility type indicated that a VL test had been conducted during the 12 months prior to treat all implementation. Patients at central hospitals and clinics were significantly more likely to have a VL test result recorded than patients at decentralized sites (64 vs 52 percent; Figure 2). Records of VL testing did not differ among new and existing ART patients nor between female and male patients.

\section{Viral suppression was high among patients tested in both types of facilities.}

Among the 566 patients with documented test results, VL outcomes did not vary significantly between facility types (Figure 2). Overall, 90 percent of tested clients were virally suppressed, and 85 percent had undetectable viral loads.

Figure 2 Client-level VL outcomes during past 12 months

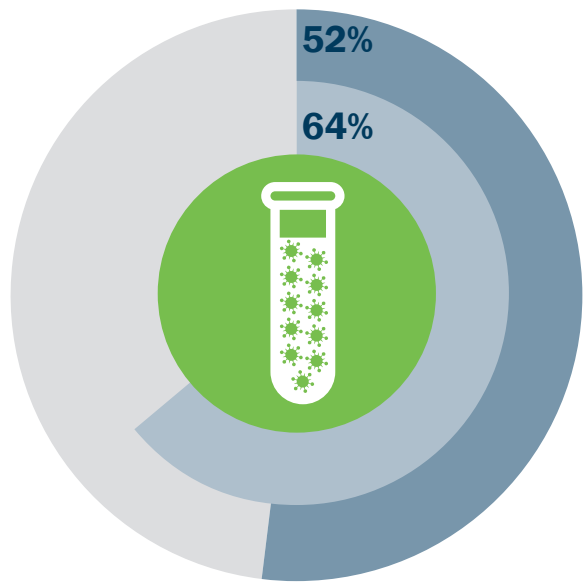

Received VL test ${ }^{* *}$

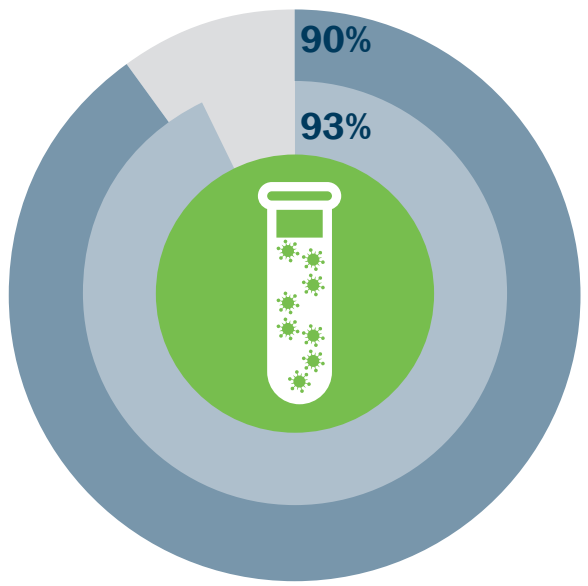

Achieved viral suppresssion ${ }^{\dagger}$

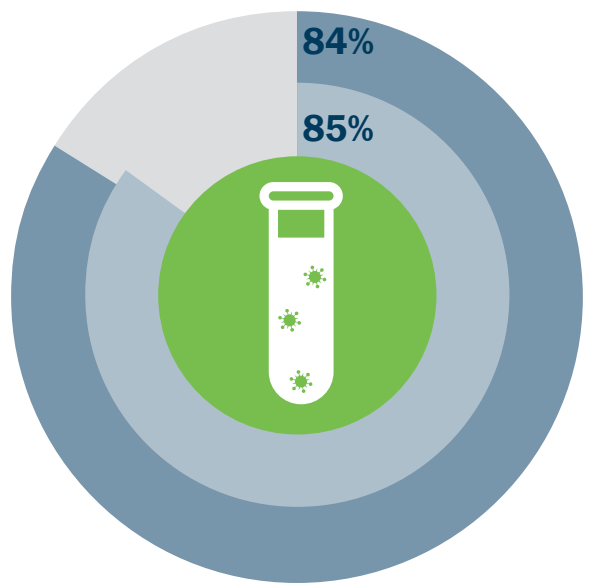

Achieved undectable $\mathrm{VL}^{\dagger}$

\section{Centralized $\square$ Decentralized}

$* * p<0.001$; ${ }^{\dagger}$ among 566 clients who received VL test in past 12 months 


\section{CONCLUSION}

These data show that the facilities surveyed reached two critical milestones: over 90 percent of ART patients were retained in care after 12 months and 90 percent of clients who received a VL test had achieved viral suppression.

The comparability of patient retention and viral suppression between centralized and decentralized sites suggests that the quality of basic ART services available through primary health care centers in rural Namibia is likely similar to services in larger hospitals. Therefore, service decentralization merits further attention and investment as a mode of improving access to HIV care and treatment services in Namibia, particularly as treat all enables more patients to initiate ART.

Despite these successes, there is room for improvement. Forty percent of all ART patients in our sample had no record of VL testing during the 12 months preceding treat all adoption. If, in fact, 40 percent of patients did not have a VL test in the preceding year, this may facilitate the development of drug resistance by allowing treatment failure to go unnoticed. Moreover, VL testing was one measure in which decentralized health centers lag considerably behind district hospitals.

While there were no significant differences in HIV outcomes between male and female patients, the difference in ART uptake by men and women is notable, particularly in decentralized facilities where 72 percent of our sample were women. This difference may suggest a need to examine why many men living with HIV are not accessing ART care and how services can better attract men.

\section{RECOMMENDATIONS}

\author{
The Government of Namibia should continue \\ to expand task-shifting and service \\ decentralization in order to make HIV \\ services more efficient and accessible. \\ The high rates of patient retention and $\mathrm{VL}$ \\ suppression observed, and comparability of \\ ART outcomes across facility types suggest that \\ decentralizing ART services is effective and may \\ help expand access to ART under treat all. The \\ resultant progress toward achieving UNAIDS 90- \\ 90-90 targets is commendable.
}

\section{Additional support is needed to understand the factors contributing to low recording of VL testing, particularly in decentralized clinics. \\ It would also be useful to conduct a focused study of viral suppression levels among patients with no recorded VL test results.}

\section{Additional analysis is needed to understand whether missing a scheduled ART visit is associated with a gap in antiretroviral medication adherence as well as other clinical outcomes.}

\section{REFERENCES}

\begin{abstract}
${ }^{1}$ World Health Organization. 2015. "Guideline on when to start antiretroviral therapy and on pre-exposure prophylaxis for HIV," in Guideline on When to Start Antiretroviral Therapy and on Pre-exposure Prophylaxis for HIV. Geneva: World Health Organization.

${ }^{2}$ Ministry of Health and Human Services. 2016. National Guidelines for Antiretroviral Therapy, 5th Edition. Windhoek: Ministry of Health and Human Services.
\end{abstract}

\footnotetext{
Suggested citation: Project SOAR. 2018. "Namibia has a strong foundation for implementing the treat all guidelines and reaching the UNAIDS 90-90-90 targets," Project SOAR Results Brief. Washington, DC: Population Council.
}

Project SOAR is a five-year (September 2014-September 2019) cooperative agreement funded by the President's Emergency Plan for AIDS Relief and the U. S. Agency for International Development (Agreement No. AIDOAA-A-14-00060). SOAR is able to accept funding from all USAID accounts.

Population Council leads the Project SOAR consortium in collaboration with Avenir Health, Elizabeth Glaser Pediatric AIDS Foundation, the Johns Hopkins University, Palladium, and The University of North Carolina at Chapel Hill.
Project SOAR/Population Council 4301 Connecticut Avenue, NW, Suite 280

Washington, DC 20008

Tel: +12022379400

e-mail: ProjectSOAR@popcouncil.org projsoar.org

(C) Population Council, March 2018 